\title{
Pertumbuhan dan Produksi Padi Varietas Inpara-3 pada Tanah Tergenang yang Diberikan Abu Batubara
}

\section{(Growth and Production of Inpara-3 Varieties Paddy in Flooded Soils Given Coal Ash)}

\author{
Muhammad Helmy Abdillah ${ }^{1)}$, Akhmad Rizalli Saidy, ${ }^{2)}$ \& Raihani Wahdah ${ }^{3)}$ \\ ${ }^{1)}$ Program Studi Budidaya Tanaman Perkebunan, Politeknik Hasnur \\ abdillah.helmy21@gmail.com \\ ${ }^{2)}$ Program Studi Ilmu Tanah Fakultas Pertanian Universitas Lambung Mangkurat \\ asaidy@unlam.ac.id \\ ${ }^{3)}$ Program Studi Agronomi Fakultas Pertanian Universitas Lambung Mangkurat \\ raihani.wahdah@ulm.ac.id
}

\begin{abstract}
ABSTRAK
Peningkatan produksi tanaman padi selalu dilakukan dengan berbagai upaya diantaranya, pemanfaatan lahan marginal dengan penggunaan amandemen tanah dan penggunaan varietas unggul. Tujuan penelitian ini, mencoba memanfaatkan abu terbang dari pembakaran batubara sebagai bahan amandemen untuk tanah-tanah tergenang yang berasal dari lahan tadah hujan, lahan pasang surut dan lahan gambut untuk meningkatkan keragaan pertumbuhan dan produksi padi varietas Inpara-3. Metode penelitian menggunakan rancangan acak lengkap faktorial tersarang dengan 2 perlakuan yaitu tanah tanpa diberikan abu batubara $\left(0\right.$ t.ha $\left.a^{-1}\right)$ dan tanah yang diberikan abu batubara (60 t.ha $\left.a^{-1}\right)$ dengan 4 ulangan pada setiap jenis tanah dan perlakuannya. Perlakuan abu batubara yang diberikan adalah 60 t.ha $a^{-1}$ 309,36 g.pot tanah ${ }^{-1}$ untuk tanah tadah hujan, 374,52 g.pot tanah ${ }^{-1}$ untuk tanah rawa pasang surut dan 519,56 g.pot tanah ${ }^{-1}$ untuk tanah rawa gambut, sehingga terdapat 24 satuan percobaan. Perlakuan setiap jenis tanah sesuai kapasitas bulk densitynya. Penelitian dilaksanakan di Rumah Kaca Fakultas Pertanian ULM Banjarbaru, Kalimantan Selatan pada bulan Mei-Oktober 2018. Hasil penelitian menunjukkan tanaman padi, yang ditanam pada tanah gambut diberikan abu batubara menunjukkan hasil positif pada semua parameter pengamatan, namun hasilnya berbeda dengan tanaman padi yang ditanam pada tanah lahan pasang surut yang diberikan abu batubara, hanya menunjukkan hasil positif pada parameter tinggi tanaman, pertambahan tinggi, jumlah anakan, berat kering gabah, dan akar terpanjang tanaman padi. Analisa keragaan pertumbuhan dan produksi juga dilakukan pada tanaman padi yang ditanam pada tanah tadah hujan, terlihat berpengaruh positif hanya pada parameter berat kering gabah dan berat kering tanaman (tanpa akar, malai dan gabah).
\end{abstract}

Kata kunci: Ameliorasi, padi, rawa.

\section{ABSTRACT}

Increasing rice production is always encouraged by various efforts including, utilization of marginal land with the use of land amendments and the use of superior varieties. The purpose of this study is to try to utilize fly ash from coal combustion as an amendment material for stagnant soils originating from lebak land, tidal land, and peatland to improve the performance and growth of rice in Inpara-3 varieties. The research method uses a completely randomized factorial design with two treatments, namely soil without coal ash $\left(0 t . h a^{-1}\right)$ and land that is given coal ash $\left(60 t . h a^{-1}\right)$ and four replications in each soil type and its treatment. The coal ash treatment given was 60 t.ha-1 (309.36 g.pot soil $^{-1}$ for lebak marshland, 374.52 g.pot soil ${ }^{-1}$ for tidal swamp soils and 519.56 g.pot soil ${ }^{-1}$ for peat swampland, so there are 24 units of the experiment. Treatment of each type of land according to its bulk density capacity. The research was conducted in the Greenhouse Faculty of Agriculture ULM Banjarbaru, South Kalimantan, in May-October 2018. The results showed rice plants, which were planted on peat soils given coal ash, showed positive effects on all parameters observed. Still, the results were different from rice plants that were planted on tidal land soils provided coal ash, only showed positive results on parameters of plant height, height increase, number tillers, grain dry weight, and longest roots of rice plants analysis of growth and production performance are also carried out on rice plants planted on a le tub, seen to have a positive effect only on the parameters of dry grain weight, plant dry weight (without roots, panicles, and grains). 
Keywords: Amelioration, paddy, swamp.

Article History Submitted: March 27, 2020 Accepted: May 14, 2020
Approved with minor revision: May 1, 2020

Published: May 25, 2020

\section{PENDAHULUAN}

Kegiatan budidaya tanaman padi di Kalimantan Selatan merupakan kegiatan prioritas agar terciptanya ketahanan pangan nasional dan menjadikan Indonesia sebagai lumbung pangan dunia pada tahun 2045 . Peningkatan produksi tanaman padi selalu dilakukan dengan berbagai upaya diantaranya, pemanfaatan lahan rawa marginal yang diupayakan produktivitasnya dengan ditanami padi varietas unggul. Pengujian Padi Varietas Inpara-3 telah dilakukan sebagai varietas yang cukup toleran terhadap cekaman abiotik khususnya di Kabupaten Barito Kuala didaerah pasang surut dengan katagori tipe luapan air B (Koesrini et al., 2017), karena mampu beradaptasi dengan lingkungan marginal dan menghasilkan produksi yang tidak kalah dengan varietas lokal. Dalam implementasinya di lapangan, terlihat hasil bahwa cukup sulit memenuhi harapan dan target agar Padi Varietas Inpara-3 mampu berproduksi maksimal sesuai potensinya. Hal ini disebabkan oleh tingginya cekaman abiotik pada lahan tergenang, sehingga cukup sulit menghasilkan produksi yang lebih baik dari varietas lokal yang mampu beradaptasi pada cekaman tersebut. Penggunaan amandemen tanah dirasa perlu untuk mendorong tercapainya potensi optimal dari Padi Varietas Inpara-3. Dalam mendorong potensi Padi Inpara-3 di lahan rawa marginal, maka diperlukan penambahan bahan ameliorasi tanah yang memiliki kemampuan untuk memperbaiki $\mathrm{pH}$ tanah dan memantapkan bulk density tanah dengan kandungan ion basa tinggi agar akar tanaman dapat berkembang dengan maksimal. Oleh karena itu, perlu dilakukan penelitian tentang penambahan bahan amelioran berupa abu dari hasil pembakaran batubara dari boiler pembangkit listrik tenaga uap.
Bahan amandemen tanah yang cocok pada tanah dengan kondisi masam dan tergenang, harus memiliki sifat basa dan mengandung elemen penting untuk mengoptimalkan keberadaan hara pada tanah tersebut sehingga tersedia untuk tanaman. Amandemen tanah yang cukup potensial digunakan yakni abu batubara. Berdasarkan berbagai penelitian, abu terbang batubara memiliki kemampuan dalam meningkatkan $\mathrm{pH}$ tanah, menambah dan menyediakan unsur hara yang pada akhirnya meningkatkan kapasitas pertumbuhan dan produksi tanaman Padi (Singh et al., 2011; Priatmadi et al., 2015; Susilo, 2015; Saputra, 2016; Abdillah, 2018).

Tujuan penelitian ini, adalah untuk mengetahui pengaruh pemberian abu terbang dari pembakaran batubara sebagai bahan amandemen terhadap pertumbuhan dan produksi padi Inpara-3 pada tanah yang berasal dari lahan tadah hujan, lahan pasang surut dan lahan gambut

\section{METODE PENELITIAN}

Penelitian ini dilakukan pada Mei Oktober 2018 di Rumah Kaca Fakultas Pertanian ULM, Banjarbaru Kalimantan Selatan dengan model statistik rancangan acak lengkap. Tanah diambil dari tiga tempat di Kalimantan Selatan guna mewakili daerah yang sesuai dengan tipologi lahan yang diteliti. Tanah pada lahan rawa tadah hujan diambil dari Desa Timbaan, Kab. Tapin. Tanah pada lahan pasang surut diambil dari Desa Tinggiran II luar, Kab. Barito Kuala. Tanah pada lahan gambut diambil dari Desa Pangkoh Hulu, Kab. Pulang Pisau. Tanah yang telah diambil dari tiga tipologi lahan tersebut, kemudian ditimbang seberat $5 \mathrm{~kg}$ untuk dimasukkan ke dalam ember bervolume 28 L. Selain itu, ember tersebut juga diisi dengan air murni $\left(\mathrm{H}^{2} \mathrm{O}\right)$ dengan asumsi agar ketika ditanami padi, seolah padi seperti 
hidup pada kondisi nyata dalam keadaan tergenang. Air yang digunakan juga air murni agar tidak mempengaruhi sifat kimia dari tanah penelitian.

Penimbangan dan pemberian abu batubara yang akan diaplikasikan pada tiga tipologi tanah tersebut berdasarkan penyelarasan indeks bulk density dari masing-masing sampel tanah yang telah dihitung sebelum proses penanaman bibit padi. Penanaman bibit ke ember dilakukan setelah 3 pekan disemai. Penanaman dilakukan pada ember berukuran $28 \mathrm{~L}$. Pengamatan parameter dilakukan setelah tanaman dipindah ke pot (ember). Pengamatan dilakukan dengan mengamati tinggi tanaman, pertambahan tinggi dan jumlah anakan dilakukan 2 kali yakni pada saat tanaman berumur 14 hari setelah tanam (2 MTS) dan dilakukan kembali pada saat tanaman berumur 100 hari setelah tanam (14 MTS). Pada tahap pascapanen, parameter yang diamati adalah berat kering gabah, berat kering tanaman (tanpa akar, malai dan gabah), akar terpanjang, volume akar, berat kering akar, serta luas permukaan akar.

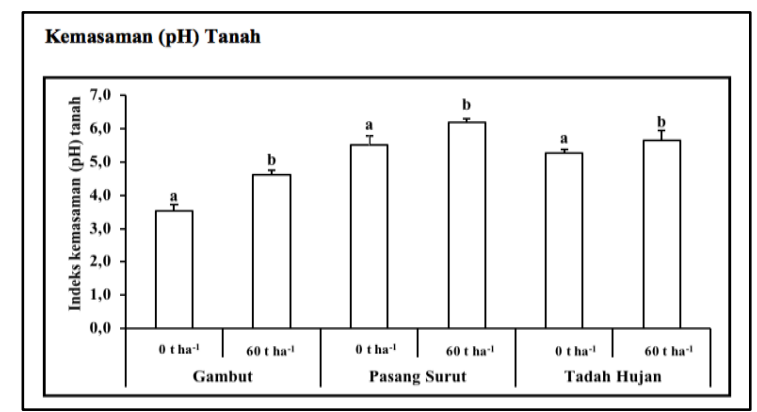

Gambar 1. Kemasaman $(\mathrm{pH})$ tanah gambut, pasang surut dan tadah hujan, tanpa dan dengan aplikasi batubara. Garis di atas batang menunjukkan simpangan baku $(n=4)$. Huruf yang sama di atas garis pada masing-masing tipologi tanah sawah menunjukkan bahwa perlakuan yang diberikan tidak berbeda pengaruhnya berdasarkan LSD Test $\alpha$ 5\%.

Peningkatan $\mathrm{pH}$ tanah (penurunan kemasaman tanah) yang terlihat pada Gambar 1, disebabkan adanya kandungan basa-basa seperti $\mathrm{NaO}, \mathrm{CaO}$ dan $\mathrm{MgO}$ serta oksida-oksida dengan konsentrasi yang bervariasi pada tanah. Hasil penelitian (Hadijah \& Retno, 2006) memperlihatkan bahwa abu batubara dari PLTU Asamasam, Kalimantan Selatan mengandung
Metode penelitian menggunakan rancangan acak lengkap faktorial tersarang dengan 24 satuan percobaan. Perlakuan yang diberikan bertujuan untuk melihat dan membandingkan hasil yang akan terjadi setelah dilakukan perlakuan pada media tanamnya. Perlakuan terdiri dari dua faktor yakni faktor perlakuan abu batubara (0 t.ha ${ }^{1}, 60$ t.ha $^{-1}$ ) dan faktor tipologi tanah yang berbeda. Data dianalisa menggunakan program SPSS 21. Perlakuan yang berbeda nyata dianalisa menggunakan uji BNT level $5 \%$.

\section{HASIL DAN PEMBAHASAN}

Hasil penelitian ini menunjukkan secara umum bahwa aplikasi abu batubara pada tiga tipologi tanah berpengaruh dalam upaya meningkatkan $\mathrm{pH}$-tanah sehingga pada akhirnya berpengaruh terhadap ketersediaan hara untuk tanaman. Kemasaman $(\mathrm{pH})$ tanah gambut, pasang surut dan tadah hujan, tanpa dan dengan aplikasi abu batubara dapat dilihat pada Gambar 1.
$2,13 \% \mathrm{CaO} ; 2,50 \% \quad \mathrm{MgO} ; 0,16 \% \mathrm{NaO}$; $19,40 \% \mathrm{Al}_{2} \mathrm{O}_{3} ; \mathrm{Fe}_{2} \mathrm{O}_{3}$ 12,52\% dan 59,3\% $\mathrm{SiO}_{2}$ pada $5 \mathrm{~g}$ sampel abu batubara yang dianalisis. Hasil penelitian serupa juga dilaporkan oleh (Haryanti, 2017) dengan mengukur sampel abu batubara sebanyak 2 $\mathrm{g}$ yang menunjukkan kandungan sebesar $2,40 \% \mathrm{CaO} ; 2,03 \% \mathrm{MgO} ; 0,06 \% \mathrm{NaO}$; $5,70 \% \quad \mathrm{Al} 2 \mathrm{O} 3 ; 14,40 \% \quad \mathrm{Fe}_{2} \mathrm{O}_{3}$ dan $\mathrm{SiO}_{2}$ 
$74,20 \%$ pada abu batubara dari PLTU

Asam-asam.

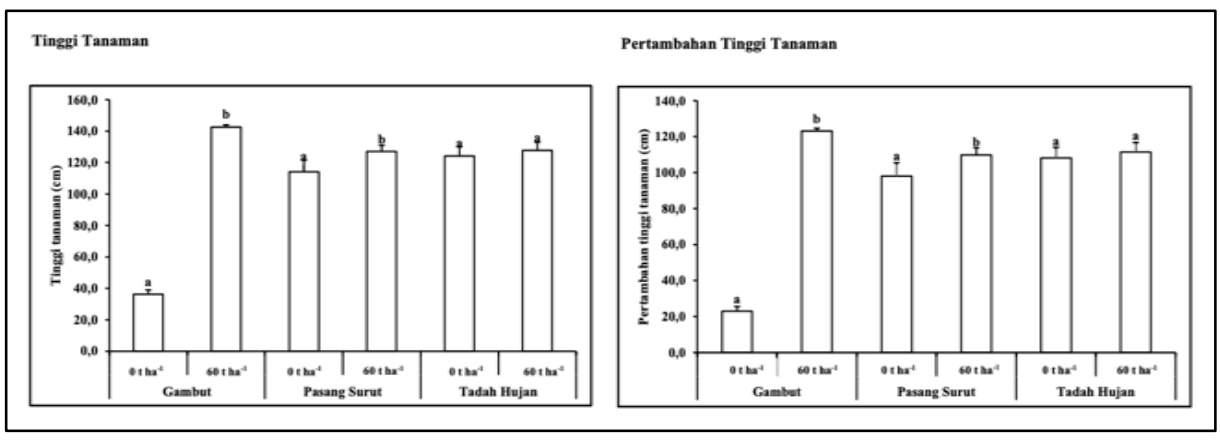

Gambar 2. Tinggi tanaman (kiri) dan pertambahan tinggi tanaman (kanan) pada tanah tanpa diberikan abu batubara dan dengan diberikan abu batubara. Garis di atas batang menunjukkan simpangan baku $(n=4)$. Huruf yang sama di atas garis pada masingmasing tipologi tanah tergenang menunjukkan bahwa perlakuan yang diberikan tidak berbeda pengaruhnya pada LSD Test $\alpha$ 5\% .

Tinggi tanaman dan pertambahan tinggi tanaman pada tanah tanpa diberikan abu batubara dan dengan diberikan abu batubara dapat dilihat pada Gambar 2 . Tinggi tanaman padi yang ditanam di tanah gambut yang diberi 60 t.ha $^{-1}$ abu batubara adalah $142,5 \mathrm{~cm}$ dibandingkan perlakuan 0 t.ha $^{-1}$ abu batubara adalah $36,3 \mathrm{~cm}$ (meningkat $75 \%$ dengan aplikasi abu batubara), sedangkan pada tanah pasang surut dan tanah tadah hujan, peningkatan hanya $10 \%$ dan $3 \%$ dari perlakuan $0 \mathrm{t} \mathrm{ha}^{-1}$ abu batubara. Pada pengukuran pertambahan tinggi tanaman pada tanah yang diberikan abu batubara 60 t.ha $^{-1}$ pada tanah gambut dan pasang surut menghasilkan pertambahan tinggi tanaman padi masing-masing adalah $123,2 \mathrm{~cm}$ dan $109,8 \mathrm{~cm}$, dari tinggi tanaman $19,3 \mathrm{~cm}$ dan $17,2 \mathrm{~cm}$ pada 2 MST dan $142,5 \mathrm{~cm}$ dan
$127,0 \mathrm{~cm}$ pada $14 \mathrm{MST}$ di dalam pot, sedangkan pada tanah gambut dan pasang surut yang tanpa pemberian abu batubara, masing-masing menghasilkan pertambahan tinggi tanaman padi adalah $22,9 \mathrm{~cm}$ dan $98,0 \mathrm{~cm}$ dari tinggi tanaman $13,4 \mathrm{~cm}$ dan $16,3 \mathrm{~cm}$ pada $2 \mathrm{MST}$ dan $36,3 \mathrm{~cm}$ dan 111,4 $\mathrm{cm}$ pada 14 MST. Pemberian abu batubara pada tanah dari lahan gambut dan pasang surut mempengaruhi tinggi tanaman, dibandingkan dengan perlakuan pada tanah dari lahan rawa tadah hujan. Hal ini disebakan oleh daya tumbuh Inpara-3 yang kurang signifikan pada tanah mineral yang terlalu tinggi pelapukan liatnya dan cenderung rendah status keharaannya. Pemberian abu batubara pada tanah mineral justru meningkatkan keterikatan antar mineral sehingga membatasi ketersediaan hara untuk memacu pertumbuhannya.
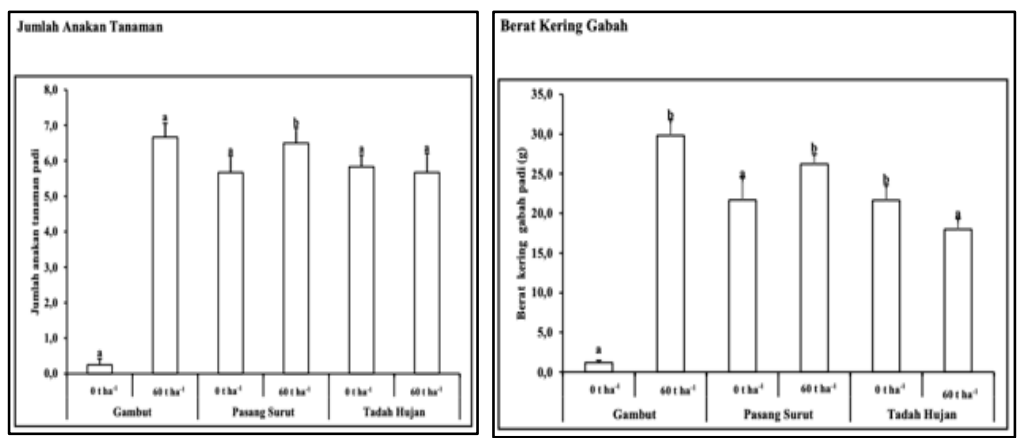

Gambar 3. Jumlah anakan (kiri) dan berat kering gabah (kanan) pada tanah tanpa diberikan abu batubara dan dengan diberikan abu batubara. Garis di atas batang menunjukkan simpangan baku $(n=4)$. Huruf yang sama di atas garis pada masing-masing tipologi 
tanah tergenang menunjukkan bahwa perlakuan yang diberikan tidak berbeda pengaruhnya berdasarkan LSD Test $\alpha$ 5\%.

Jumlah anakan dan berat kering gabah pada tanaman yang tanahnya diberi perlakuan abu batubara dan tidak diberi perlakuan abu batubara dapat dilihat pada Gambar 3. Tanah yang diberikan abu batubara berpengaruh dalam meningkatkan jumlah anakan padi dari 0,26 meningkat menjadi 6,7 pada tanah gambut dan dari 5,7 menjadi 6,5 pada tanah pasang surut. Pada tanah tadah hujan aplikasi abu batubara tidak menunjukkan pertambahan anakan. Persentasi peningkatan jumlah anakan tanaman dengan pemberian abu batubara pada tanah gambut dan pasang surut adalah masing-masing $96 \%$ dan 13\%. Pada peubah berat kering gabah mengalami peningkatan dari 1,2 g menjadi 30,0 g pada tanah gambut dan dari 22,0 g menjadi 26,2 g pada tanah pasang surut dengan aplikasi abu batubara. Pada tanah tadah hujan aplikasi abu batubara tidak mampu meningkatkan berat gabah kering padi, justru pemberian abu batubara di tanah tadah hujan menghasilkan perkembangan berat kering gabah padi yang lebih rendah sebesar 20\% dibandingkan perlakuan pada 0 t.ha ${ }^{-1}$. Pertumbuhan jumlah anakan dan pengisian gabah dipengaruhi oleh faktor dasar keperluan tanaman terhadap cahaya, keharaan serta keperluan air dalam proses fotosintesis. Secara umum, ketersediaan hara dan serapan radiasi mempengaruhi pembentukan fitohormon yang merangsang pertumbuhan vegetatif. Tanaman yang cenderung menyerap banyak nitrogen, fospor dan pembentukan auksin yang mendominasi justru terlihat subur pada bagian vegetatif daripada bagian generatif seperti pengisian malai (Sutoro et al., 2016).

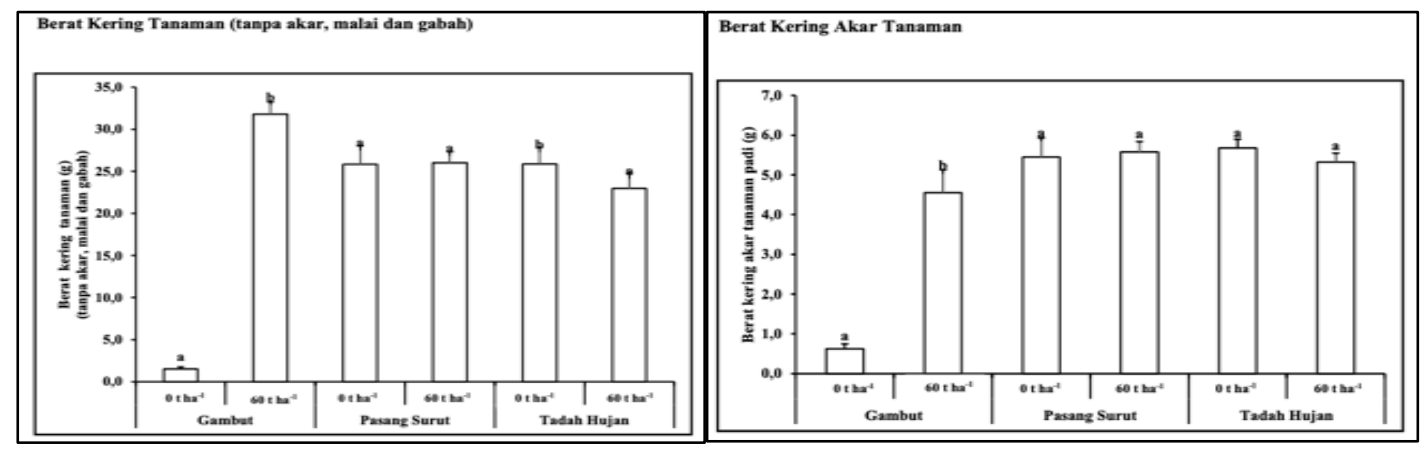

Gambar 4. Berat kering Tanaman (kiri) dan berat kering akar (kanan) pada tanah tanpa diberikan abu batubara dan dengan diberikan abu batubara. Garis di atas batang menunjukkan simpangan baku $(n=4)$. Huruf yang sama di atas garis pada masingmasing tipologi tanah tergenang menunjukkan bahwa perlakuan yang diberikan tidak berbeda pengaruhnya berdasarkan LSD Test $\alpha$ 5\%.

Pada Gambar 4, terlihat diagram batang yang menunjukkan berat kering tanaman dan berat kering akar tanaman yang tanahnya diberi perlakuan abu batubara dan tidak diberi perlakuan abu batubara. Pada tanah gambut tanpa aplikasi abu batubara, berat kering tanaman Padi adalah $1,5 \mathrm{~g}$ meningkat menjadi $32,0 \mathrm{~g}$ dengan aplikasi abu batubara. Hasil pengujian menyatakan bahwa berat kering tanaman padi pada pot (ember) percobaan media tanah pasang surut yang diberikan abu batubara tidak berbeda dengan tanpa pemberian abu batubara. Aplikasi abu batubara dengan dosis $60 \mathrm{t} \mathrm{ha}^{-1}$ pada tanah tadah hujan yang ditanami padi, justru menurunkan berat kering tanaman padi. Berat kering tanaman padi menurun sebesar 13\% akibat efek aplikasi abu batubara. Pada pemberian abu batubara hanya berpengaruh pada berat kering akar tanaman padi yang ditanam pada tanah gambut yang 
mengalami peningkatan dari $0,6 \mathrm{~g}$ menjadi $5,0 \mathrm{~g}$ (meningkat $88 \%$ ). Pada tanah pasang surut dan tadah hujan tanpa aplikasi abu batubara, berat kering akar tanaman padi adalah masing-masing 5,5 g dan 5,7 g, tidak berbeda dengan berat kering akar tanaman padi yang ditanam pada tanah pasang surut dan tadah hujan dengan pemberian abu batubara $60 \mathrm{t} \mathrm{ha}^{-1}$ yang masing-masing sebesar 5,6 g dan 5,3 g. Indeks berat kering tanaman ditentukan dari proses matabolisme tanaman seperti fotosintesis dan transpirasi tanaman yang memerlukan hara dan air, sehingga dari proses tersebut akan terbentuk pertumbuhan dan perkembangan organ tanaman yang pada akhirnya menambah berat kering tanaman secara keseluruhan termasuk pertumbuhan dan perkembangan akar.

Secara umum, proses fotosintesis dan transpirasi akan sejalan dengan pertumbuhan dan perkembangan tanaman yang optimal dengan produk fotosintat terbagi-bagi dalam tubuh tanaman. Pada Gambar 5 memperlihatkan bahwa hasil asimilasi terbagi-bagi dalam tubuh tanaman sesuai dengan keperluan tanaman yang dipengaruhi oleh faktor internal seperti metabolisme dari tanaman dan fektor eksternal seperti keadaan iklim mikro.

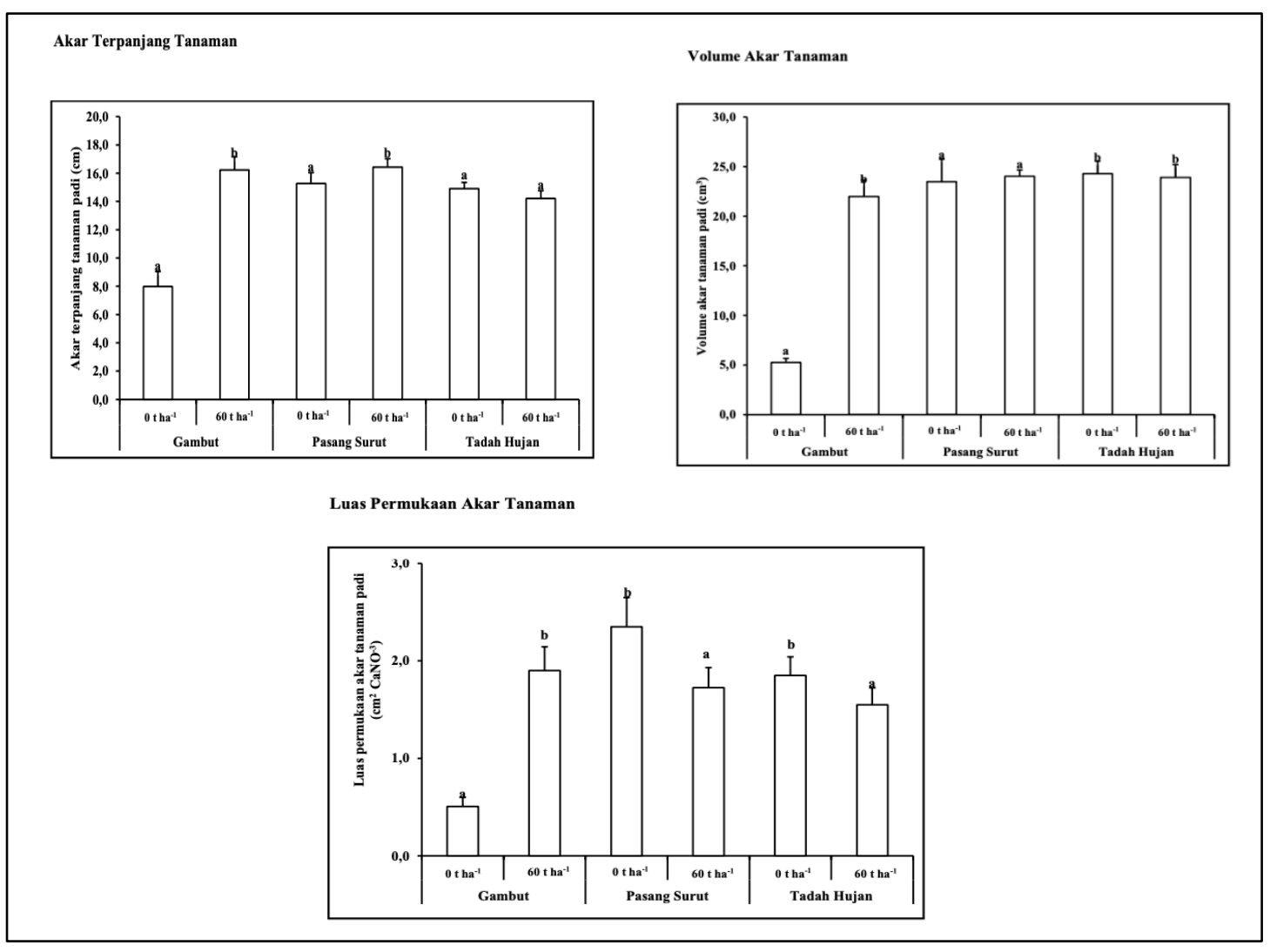

Gambar 5. Akar terpanjang (kiri), volume akar (kanan) dan luas permukaan akar (bawah) pada tanaman yang ditanam di tanah tanpa diberikan abu batubara dan dengan diberikan abu batubara. Garis di atas batang menunjukkan simpangan baku $(\mathrm{n}=4)$. Huruf yang sama di atas garis pada masing-masing tipologi tanah tergenang menunjukkan bahwa perlakuan yang diberikan tidak berbeda pengaruhnya berdasarkan LSD Test $\alpha 5 \%$.

Gambar 5 memperlihatkan bahwa pada tanah gambut tanpa pemberian abu batubara, pertumbuhan akar terpanjang tanaman padi adalah $8 \mathrm{~cm}$ meningkat menjadi $16,23 \mathrm{~cm}$ pada perlakuan aplikasi abu batubara $60 \mathrm{t} \mathrm{ha}^{-1}$. Pertumbuhan akar terpanjang tanaman padi pada tanah pasang surut tanpa pemberian abu batubara adalah $15,3 \mathrm{~cm}$, meningkat menjadi $16,4 \mathrm{~cm}$ dengan aplikasi abu batubara 60 t.ha $^{-1}$. Akar terpanjang tanaman padi yang ditanam pada tanah tadah hujan dengan aplikasi abu 
batubara sebesar 60 t.ha' ${ }^{-1}$ mencapai 14,2 $\mathrm{cm}$, dibandingkan dengan tanpa aplikasi abu batubara yakni $15 \mathrm{~cm}$, tidak ada perbedaan antar kedua perlakuan tersebut. Pemberian abu batubara dengan takaran 60 t.ha ${ }^{-1}$ pada tanah gambut berpengaruh positif terhadap volume akar tanaman padi, namun tidak pada berbeda pada tanah pasang surut dan tadah hujan. Volume akar $76 \%$ lebih besar dibandingkan dengan volume akar tanaman padi pada tanah gambut tanpa aplikasi abu batubara yang hanya $5,3 \mathrm{~cm}$. Pada tanah pasang surut dan tadah hujan dengan perlakuan tanpa aplikasi abu batubara, terlihat volume akar tanaman padi adalah masing-masing 23,5 $\mathrm{cm}$ dan $24,3 \mathrm{~cm}$, tidak berbeda dibandingkan dengan hasil pengukuran volume akar tanaman padi pada pot percobaan dengan diberi 60 t.ha ${ }^{-1}$. Pada perlakuan abu batubara 60 t.ha ${ }^{-1}$ menghasilkan volume akar yang masingmasing sebesar $24 \mathrm{~cm}^{3}$ dan $23,9 \mathrm{~cm}^{3}$

Pemberian abu batubara sebesar 60 t.ha ${ }^{-1}$. memberikan pengaruh yang beragam pada setiap tipologi tanah yang digunakan. Aplikasi abu batubara sebesar 60 t.ha $^{-1}$ di tanah gambut berpengaruh positif meningkatkan luas permukaan akar tanaman padi, yang hasilnya $2,0 \mathrm{~cm}^{2} \cdot \mathrm{gr}^{1}$ dibandingkan perlakuan tanpa abu batubara yang hanya $0,5 \mathrm{~cm}^{2} \cdot \mathrm{gr}^{-1}$ atau hasil ini lebih besar hampir $80 \%$ dari perlakuan tanpa abu batubara. Pada tanah pasang surut dan tadah hujan, pemberian abu batubara menurunkan luas permukaan akar tanaman padi dibandingkan dengan luas permukaan akar tanaman padi pada tanah yang tidak diaplikasikan abu batubara adalah masingmasing $1,67 \mathrm{~cm}^{2} \cdot \mathrm{gr}^{-1}$ dan $1,83 \mathrm{~cm}^{2} \cdot \mathrm{gr}^{-1}$

Secara umum, kondisi perakaran seperti panjang akar, volume akar dan luar permukaan akar pengaruhi oleh media tanam yang dibentuk oleh sifat kimia sehingga berimplikasi pada keadaan fisik tanah. Hal ini terjadi disebabkan ikatan kimia antar misel-misel tanah yang bermuatan anion dan kation lemah hingga kuat sehingga menyebabkan secara fisik tanah sulit terurai, dan secara kimia hal ini dapat disebabkan karena terjadinya keterikatan (kelat) unsur hara dengan logam mineral yang berlebihan. Selain itu, ion $\mathrm{H}^{+}$ yang beredar dalam tanah juga sangat mempengaruhi pertumbuhan akar tanaman dengan cara menutup semua lapisan pori permukaan kulit akar dengan logam minarel sebagai jerapannya.

\section{KESIMPULAN}

Abu terbang batubara berpengaruh positif terhadap terhadap peningkatan $\mathrm{pH}$ tanah pada tiga tipologi tanah yang diteliti. Aplikasi abu terbang batubara pada tanah dari tipologi rawa gambut dan pasang surut memberikan pengaruh positif terhadap parameter yang diamati pada tanaman padi meliputi tinggi dan pertambahan tinggi tanaman, jumlah anakan, berat kering tanaman, berat kering akar, akar terpanjang tanaman padi, namun tidak berpengaruh pada volume akar dan luas permukaan akar tanaman padi. Pengamatan pada tanaman padi dengan media tanam tanah dari tipologi tanah tadah hujan yang diaplikasikan abu batubara menunjukkan pengaruh yang tidak berbeda dibandingkan tanpa perlakuan yakni menghasilkan indeks yang lebih rendah dibandingkan dengan tanaman yang ditanam pada tanah tanpa aplikasi batubara.

\section{DAFTAR PUSTAKA}

, K., Saleh, M., \& Nurzakiah, D. S. (2017). Adaptabilitas Varietas Inpara di Lahan Rawa Pasang Surut Tipe Luapan Air B pada Musim Kemarau. Jurnal Agronomi Indonesia (Indonesian Journal of Agronomy), 45(2), 117. https://doi.org/10.24831/jai.v45i2.135 59

Abdillah, M. H. (2018). Pengaruh abu boiler pembakaran batubara terhadap sifat fisika-kimia tiga tipologi lahan rawa. AGRISAINS, 4(01), 5-10.

Hadijah, N. R., \& Retno, D. (2006). Penelitian abu batu bara sebagai pembenah tanah: Pengaruh waktu 
inkubasi terhadap parameter kualitas tanah (derajat keasaman tanah $(\mathrm{pH}-$ $\mathrm{H} 2 \mathrm{O}$ ), Mn, Fe, P-Total dan PTersedia). Jurnal Teknologi Mineral Dan Batubara, Nomor, 36.

Haryanti, N. H. (2017). Uji Abu Terbang PLTU Asam Asam Sebagai Bahan Pembuatan Bata Ringan. Jurnal Fisika Flux: Jurnal Ilmiah Fisika FMIPA Universitas Lambung Mangkurat, 11(2), 127-137.

Priatmadi, B. J., Saidy, A. R., \& Septiana, M. (2015). Soil Properties and Growth Performance of Rize (Oryza sativa L.) Grown In A Fly-Ash Amended Soil. Tropical Wetland Journal, 1(1), 1924. https://doi.org/10.20527/twj.v1i1 .13

Saputra, R. A. (2016). Pengaruh aplikasi abu terbang batubara pada jenis sawah yang berbeda terhadap perubahan sifat kimia tanah, pertumbuhan, dan produksi padi. Tesis Fakultas Pertanian Pascasarjana Universitas Lambung Mangkurat.

Singh, S., Gond, D. P., \& Pal, A. (2011). Performance of Several Crops Grown in Fly Ash Amended Soil. World of Coal Ash (WOCA) Conferences May, 9-12.

Susilo, H. (2015). Kadar klorofil daun dan pertumbuhan tanaman padi sawah di lahan pasang surut dengan aplikasi dosis abu batubara. Skripsi. Fakultas Pertanian. Universitas Lambung Mangkurat. Banjarbaru.

Sutoro, N., Suhartini, T., Setyowati, M., \& Trijatmiko, K. R. (2016). Keragaman Malai Anakan dan Hubungannya dengan Hasil Padi Sawah (Oryza sativa). Buletin Plasma Nutfah, 21(1), 9. https://doi.org/10.21082/blpn.v21n 1.2015.p9-16 